E N S A I O B I B L I O G R Á F I C O

\title{
A ReVOluÇÃo doS CRAVOS E A HISTORIOGRAFIA PORTUGUESA
}

The Carnation Revolution and the

Portuguese historiography

La Revolución de los Claveles

y la historiografia portuguesa

FRANCISCO CARLOS PALOMANES MARTINHO

Francisco Carlos Palomanes Martinho é mestre em História Contemporânea pela Universidade Federal Fluminense, doutor em História Social pela Universidade Federal do Rio de Janeiro e professor livre docente de História Ibérica da Universidade de São Paulo (fcpmartinho@gmail.com).

Artigo recebido em 1 de fevereiro e aprovado para publicação em 4 de maio de 2017. 


\title{
RESUMO
}

0 objetivo deste texto é analisar algumas questões que têm marcado a produção historiográfica portuguesa acerca do tema da transição democrática. Discute-se como os estudos históricos têm lidado com a memória social a respeito da experiência autoritária em Portugal. Em seguida, examina-se correntes interpretativas que colocam em questão o significado e a profundidade das mudanças desencadeadas na esteira da transição democrática. Pretende-se também chamar atenção para um debate que, marcado pelos impactos do tempo presente, está longe de se esgotar.

Palavras-CHAVE: revolução, transição, historiografia.

\begin{abstract}
The objective of this text is to analyze some questions that have been important for the Portuguese historiographical production about the democratic transition theme. It discusses how historic studies have been dealing with the social memory related to the authoritarian experience in Portugal and examines different interpretations that question the meaning of the changes that happened as a consequence of the democratic transition. We intend, as well, to draw attention to a debate that, marked by the present time, is still far from over.
\end{abstract}

KEYwORDs: revolution, transition, historiography.

\section{RESUMEN}

El objetivo de este artículo es analizar algunas cuestiones que tienen importancia en la producción historiográfica portuguesa a respecto del tema de la transición democrática. Discutiremos como los estudios históricos tienen lidiado con la memoria social a respecto de la experiencia autoritaria en Portugal. Después examinaremos las corrientes interpretativas que ponen en cuestión el significado y la profundidad de las mudanzas desencadenadas en el proceso de transición democrática. Pretendemos también llamar la atención para un debate que, marcado pelos impactos del tiempo presente, está lejos de agotarse.

Palabras Clave: revolución, transición, historiografía. 
golpe de Estado de 25 de abril de 1974 derrubou uma das ditaduras mais duradouras da história do Ocidente. Iniciada em 28 de março de 1926 como regime militar, sua longa durabilidade acompanhada do relativo atraso econômico e cultural português fez com que a queda do Estado Novo, já sob o consulado de Marcello Caetano, causasse tanto surpresa quanto curiosidade na opinião pública internacional. Segundo Fernando Rosas, é indiscutível o susto provocado pela Revolução dos Cravos nas chancelarias e na administração americana: "antena da CIA em Lisboa estaria desactivada" (Rosas, 2004a: 129-30). Em seguida ao golpe, logo surgiram análises, ora acerca da natureza da ditadura derrubada, ora acerca do processo revolucionário e do regime democrático que veio a seguir. Os primeiros estudos tenderam a compreender a transição portuguesa como um fenômeno ligado às demais transições do sul da Europa, da Espanha e da Grécia (O'Donnel, Schmitter \& Whitehead, 1988; Schmitter, 1999). Importantes estudiosos portugueses, em trabalhos subsequentes, continuam a perceber a redemocratização como parte integrante da "vaga democrática" de meados da década de 1970 (Pinto \& Teixeira, 2005). Sem descaracterizar este modelo interpretativo, seguramente importante, procurarei me ater às análises que pensam a transição portuguesa a partir de suas características endógenas, internas à política portuguesa entre o final da década de 1960 e a primeira metade da década seguinte. Discutirei, também, as interpretações acerca do legado da Revolução dos Cravos no Portugal contemporâneo.

Igualmente fortes nos primeiros anos de democratização, foram os estudos que guardam em suas análises algo de militância, evocativa de um 25 de Abril quase que predestinado a acontecer. E que, em certa medida, excluem como falsas outras formas de entendimento da Revolução Portuguesa. Como esse modelo de análise permanece, havendo mesmo certo renascer de perspectivas militantes entre os historiadores portugueses, elas serão igualmente consideradas como representativas de certo campo historiográfico.

De uma forma geral, dois grandes modelos de análise estão presentes nos textos que aqui serão tratados. 0 primeiro modelo privilegia a análise da gestão de Marcello Caetano e dos limites e potenciais da modernização por ele conduzida nos cinco anos e meio em que esteve à frente do Executivo português. Neste sentido os enfoques incidem sobre a correlação de forças do marcelismo, o peso dos conservadores e dos reformistas, bem como o comportamento de Caetano frente a cada um dos lados. 0 segundo modelo procura discutir a 
transição em si, do peso maior ou menor da ruptura e de suas consequências para o processo constitucional. O papel mais ou menos peculiar do marcelismo e o sentido da revolução que se seguiu ao 25 de abril são temas tanto mais controversos quanto menos estudados. Por isso, a escolha de tratá-los.

\section{A MODERNIZAÇÃO MARCELISTA: LIMITES E POSSIBILIDADES}

É relativamente consensual entre os historiadores que o breve consulado de Marcello Caetano viveu uma "experiência de modernidade" (Berman, 1986). Seu significado, entretanto, variou. Assim como existem trabalhos que veem o marcelismo como um processo de transição falhado ou bloqueado, outros, em sentido inverso, afirmam a inexistência de qualquer intenção liberalizante ou mesmo reformadora.

Sobre o tema, Fernando Rosas alerta para dois perigos recorrentes na historiografia a respeito do último governo do Estado Novo. Em primeiro lugar a tendência a ver o marcelismo exclusivamente a partir de seu colapso, desconsiderando as nuances ou os anúncios de alteração de rumo do início do governo Marcello Caetano. Em segundo lugar a tentação de ver o marcelismo a partir do currículo de Caetano e de seu histórico de permanente compromisso, ainda que crítico com o Estado Novo e mais ainda seu passado integralista.

No primeiro caso, este tipo de abordagem desconsidera que o "marcelismo" está para além da conjuntura de 1968-1974. Foi, na verdade, um "partido informal", constituído lenta e continuamente, sobretudo a partir da segunda metade da década de 1940. Ao mesmo tempo em que aspiravam chegar ao poder legalmente, por dentro das instituições da ditadura, apontavam para um projeto modernizante e tecnocrático, de reformas que ultrapassavam a mera continuidade com relação a Salazar. Mesmo depois da saída de Marcello Caetano do governo em 1958 e sua "travessia no deserto" por dez anos, os marcelistas estiveram presentes com destaque no regime, particularmente no último ministério de Oliveira Salazar, o que teria influenciado decisivamente na nomeação de Caetano quando da impossibilidade física do velho ditador. A questão que se coloca, segundo Rosas, é: por qual motivo as tímidas reformas anunciadas em 1968/69 não tiveram continuidade e foram bloqueadas? Deste modo, a seu ver, havia uma intenção reformista que entretanto não chegou às suas últimas consequências (Rosas, 2004b: 10-2).

No segundo caso, as condições de ideólogo e quadro do regime e de integralista na juventude não devem, para Rosas, ser entendidas como impedimento para alguma descontinuidade. Lembra ainda Rosas que personagens como Adolfo Suárez, ex-chefe do partido único franquista, ou Mihail Gorbachov, ex-chefe da KGB, foram personagens de transições cujos 
currículos em nada apontavam para uma descompressão das ditaduras espanhola e soviética, respectivamente (Rosas, 2004b: 12-3).

Com este olhar não concorda Luis Reis Torgal. Em artigo sobre o marcelismo e o Estado Novo, indaga a respeito da correção de utilizarmos o sufixo ismo para a caracterização do consulado de Marcello Caetano. Afinal de contas, ele designaria uma ação ou uma forma de agir e pensar original em comparação com o passado. Afirma que mantém o emprego do "marcelismo", pois, ainda que discutível o seu emprego, "alguma coisa de diferente aconteceu" e, ao mesmo tempo, ele se tornou tão corrente que é quase impossível conter o seu emprego (Torgal, 2009: 615-6).

Assim, para a análise do que foi o período Marcello Caetano, Torgal diverge de Rosas em dois aspectos importantes. 0 primeiro é que para ele as interpretações historiográficas que tenderam ver nos anos entre 1968 e 1974 alguma tentativa de transição liberalizante esquecem o passado de Marcello Caetano, abdicam de uma "perspectiva mais alargada" do último presidente do Conselho, a seu ver "fundamental para entender o marcelismo". Por este motivo procura destacar a origem integralista de Marcello Caetano desde a sua participação, aos 20 anos de idade, na revista Ordem Nova, seu papel como ideólogo do corporativismo e seu entusiasmo quanto ao papel da Mocidade Portuguesa (MP) na formação de uma elite, de novos dirigentes, responsável pela afirmação do "espírito heroico contra o espírito burguês", como súmula de todos os princípios da "revolução", entre os quais destacamos a "unidade nacional contra o espírito de partido ou de classe" e "a disciplina e a lealdade ao Chefe contra a desordem de um Estado acéfalo e de mil opiniões diversas" (Torgal, 2009: 633-61).

Estes valores manter-se-iam quando de seu governo. Em nada tentara mudar de fato, a não ser do ponto de vista "cosmético", como por exemplo nas alterações de nome da PIDE (Polícia Internacional de Defesa do Estado) para DGS (Direcção Geral de Segurança) sem qualquer abrandamento do aparato repressivo. Ou ainda na mudança de nome da União Nacional, o partido único do regime, para Acção Nacional Popular, entendida como uma "organização antipartidária" (Torgal, 2009: 671-3). Aliás, no que concerne à questão da organização do Estado, Torgal ressalta a recusa de Marcello Caetano ao sufrágio universal, que subordina a sociedade ao indivíduo. Desta forma, a Revolução Corporativa era o projeto de organização institucional que o Estado Novo deveria realizar de fato e radicalmente (Torgal, 2009: 64954). Em outras palavras, a Revolução Corporativa não tinha por que ser alterada ou sequer reformada. 0 papel que Caetano se dava era, pois, o de dar continuidade ao salazarismo.

Do ponto de vista da ação governativa, Torgal lembra as medidas "espetaculares" como os retornos a Portugal de dois importantes exilados: o bispo do Porto, d. António Ferreira Gomes, e Mário Soares (Torgal, 2009: 621). Tais medidas não impediram, por exemplo, a 
repressão da DGS à vigília pela paz realizada por católicos progressistas na Capela do Rato, em Lisboa, em dezembro de 1972 (Torgal, 2009: 623-24). Por fim, para Torgal, a entrada dos liberais na Assembleia Nacional não teve em nada o intuito de criar "condições favoráveis ao debate político" (Torgal, 2009: 621). Daí a frustração de seus membros e a rápida migração destes para o campo oposicionista. Sobre este tema também concordam dois importantes estudiosos da Ala Liberal e de sua relação tensionada com Marcello Caetano: Tiago Fernandes (2006) e J. M. Reis (2010). É certo que Marcello Caetano sofreu a oposição tanto da esquerda como da ultradireita, de modo que a imagem de "liberal" não foi inventada após sua queda ou nos anos que se seguiram ao 25 de Abril. Ela já existia e causava incômodo em setores mais conservadores e tradicionalistas do regime (Marchi, 2014: 327-356; Marchi, 2009). Esta situação teria provocado um rápido isolamento de Marcello Caetano, cercado que estava pelos dois lados diametralmente opostos do campo ideológico. Na feliz expressão de Reis Torgal, ele não estava "orgulhosamente só", como antes pronunciara Salazar, mas apenas "tristemente só" (Torgal, 2009: 624). Esta condição, entretanto, não altera o fato de que inexistia, da parte do último presidente do Conselho, qualquer vontade de conduzir o país a uma transição, daí a seu ver o título infeliz do livro de Fernando Rosas e Pedro Ayres de Oliveira, A transição falhada. Não foi em nada falhada, pois sequer havia projeto de transição (Torgal, 2009: 617). Assim, o marcelismo não passou de um "Estado Novo sem Salazar". Deste modo, o anúncio da "renovação na continuidade", feito por Marcello Caetano em seu discurso de posse, foi na prática mais "continuidade" do que "renovação" (Torgal, 2009: 673).

A temática da continuidade/descontinuidade é corrente nas historiografias que tratam de transições e revoluções e de uma forma geral são acompanhadas de larga conotação ideológica. Portugal não foi exceção. No que diz respeito ao último período do Estado Novo, objetivo analisar em que medida a governação de Marcello Caetano foi vista pelos historiadores como um momento de alteração de rumo do ponto de vista das estruturas econômicas e sociais vigentes até então. Em segundo lugar, na medida em que seu governo se constituía a partir de um legado autoritário, as interpretações acerca do papel de Caetano em favor de reformas liberais merecem análise.

Quanto ao primeiro aspecto, parece não haver dúvidas de que existia um empenho de fato no sentido de reformas modernizadoras. As mudanças econômicas, mesmo que com limites, foram reais. David Corkill defende a tese de que - ainda que não tenha sido a razão principal - o desempenho da economia portuguesa foi também um fator que contribuiu para a queda do Estado Novo. Para este historiador, o rápido desenvolvimento econômico iniciado na década de 1960 (início da "abertura à Europa") registrou taxas de crescimento próximas dos $8 \%$ ao ano. A despeito de uma historiografia que no imediato pós-25 de Abril exagerava 
nas tintas a respeito do atraso econômico, a adesão à AELC (Associação Europeia de Livre Comércio) em 1960, os investimentos em infraestrutura nas áreas de energia e eletrificação e, por fim, a abertura ainda que limitada ao capital estrangeiro teriam sido responsáveis por sensíveis alterações no quadro econômico português. Em seguida à saída da Inglaterra da AELC, Portugal tratou de imediatamente estabelecer uma parceria com a CEE (Comunidade Econômica Europeia), ainda que não sua adesão formal, impedido que estava devido às naturezas do regime e do sistema colonial. No entanto, é fato que o legado de uma longa ditadura com um modelo de gestão econômica profundamente autárquico nunca foi de todo superado. Ao mesmo tempo, a crise do petróleo de 1973 foi capital para um país que, em nome dos investimentos na industrialização, dependia crescentemente do produto. Soma-se a isso a permanência de uma mão de obra desqualificada, uma agricultura atrasada e pouco produtiva e um mercado colonial em nada exigente (Corkill, 2004: 213-32). A despeito desses problemas tradicionais, as consequências da crise dos anos 1970 foram inerentes a um país "em processo de modernização". Exatamente o contrário da crise de 1929 e de seus impactos em Portugal, não somente retardados como também profundamente acanhados (Martinho, 2009: 305330; Rosas, 2000). Um país mais integrado no sistema econômico mundial necessariamente sofria consequências mais diretas de suas eventuais crises. Seria então um país dual? Este é um tema que merece investigações futuras e que ainda não foi devidamente debatido pelos historiadores. De qualquer modo o regime ainda não se encontrava disposto a abrir mão do modelo autárquico e corporativo. A modernização emperrada evidenciava o contraste entre segmentos que, mantenedores da ditadura, demonstravam descompasso quanto à forma de geri-la (Corkill, 2004: 231).

Outros aspectos importantes a evidenciar o esforço de Marcello Caetano em favor da modernização portuguesa foram a política educacional e as reformas adotadas por seu ministro da Educação, José Veiga Simão. Ainda que as alterações no campo educativo tenham incidido também sobre os ensinos básico e dos liceus, a maioria dos estudiosos aponta sobretudo para as alterações ocorridas no ensino superior como a marca de maior importância no ministério ocupado por Veiga Simão. 0 novo ministro utilizava-se de um discurso que fazia corar os segmentos mais conservadores. Apontava para a necessidade de uma universidade crítica onde pudessem conviver pacificamente "professores e estudantes das mais diversas formações ideológicas". Simão defendia igualmente uma reforma na carreira docente que, por exemplo, contemplasse o reconhecimento do grau de doutor obtido em universidades estrangeiras (Proença, 2004: 243). 0 processo de europeização, portanto, ia para além da gestão econômica. De acordo com Cândida Proença, a perspectiva de Veiga Simão era parte integrante dos discursos originários do liberalismo, quando a implantação de um sistema 
nacional de ensino era determinante para a "participação consciente na vida pública" e necessária a todos os cidadãos. Este discurso, originário da geração de 1870, teria perdido sua continuidade com a ditadura inaugurada em 1926, sobretudo a partir da ascensão de Oliveira Salazar ao cargo de presidente do Conselho de Ministros (Proença, 2004: 258-9). Neste caso, percebemos uma alteração no campo dos valores por dentro do próprio regime, na medida em que um ministro de Estado era o porta-voz de um discurso que havia sido, em parte, a razão do golpe militar que derrubara o regime republicano de 1910-1926. No entanto, tratava-se de um discurso em nada unânime, razão de seu bloqueio no campo político. É curioso, pois, que parte de seu projeto voluntarioso e otimista tenha sido levada à prática apenas quando da democratização pós- 25 de Abril (Proença, 2004: 260). Em termos práticos, as medidas objetivadas por Veiga Simão e realizadas a posteriori eram, entre outras: institucionalização da carreira de investigação científica ligada à carreira docente; fomento e intercâmbio científico com centros estrangeiros de renome internacional; preenchimento das vagas de professores até então ociosas, etc. (Proença, 2004: 248-9).

A despeito das objeções de Torgal, parece, pois, que uma experiência de modernidade durante a governação de Marcello Caetano, mesmo bloqueada, foi percebida pela maioria dos historiadores portugueses. Eles apontam para uma proximidade maior frente à Europa, para uma política de quebra - ou de flexibilização - do modelo autárquico estatista, e para as reformas do ensino protagonizadas por seu ministro da Educação Nacional.

A transição política portuguesa, vista a partir dos eventuais esforços modernizantes de Marcello Caetano, é entendida, pois, pela historiografia de forma ambivalente. De um lado, é reconhecido certo empenho no sentido da alteração do atraso estrutural do país. Alteração esta que veio acompanhada inclusive, como no caso de seu ministro da Educação, de algum discurso democratizante e mesmo participativo da sociedade. Mas a tensão modernizadora do regime a partir do final da década de 1960 não é necessariamente democrática, haja vista a existência de inúmeras correntes, ainda que modernizadoras, em nada comprometidas com a democracia. Em outras palavras, ser moderno não significa ser democrático. Burke ou Ranke, por exemplo, eram pensadores comprometidos com a modernidade e, portanto, distantes de qualquer tentativa de restauração do passado. Muitas de suas ideias foram geradas no seio do próprio lluminismo e por eles reinterpretadas. Por exemplo, a argumentação iluminista contra o absolutismo régio será utilizada contra o absolutismo do povo: "nem tirania do rei, nem tirania do povo". Em outras palavras, refiro-me aqui a autores caros ao pensamento conservador e igualmente adequados à modernidade do século XIX (Teixeira da Silva, 2000). Ainda assim, para o caso a que se volta este texto, permanece a indagação acerca das reais intenções democratizantes de Marcello Caetano. Já sabemos que a história é pródiga em 
exemplos de reformistas com passado autoritário e de autoritários com passado reformista. Caetano foi responsável pelo retorno ao país de importantes opositores do regime então exilados. Aproximou-se, ainda que com reserva, da Europa Ocidental. No entanto, é fato também que foi responsável pelo bloqueio de qualquer possibilidade pluralista ou democrática. E que a incorporação de modernos junto aos quadros do regime não objetivava mais que a intenção de controlá-los. Quem sabe, então, não é exatamente esta ambivalência a chave para o entendimento do marcelismo?

\section{A HistORIOGRAFIA DA TRANSIÇÃO: QUAL REVOLUÇÃO?}

S e a transição portuguesa, vista a partir do consulado de Marcello Caetano, é ambígua do ponto de vista das análises historiográficas, não menos complexas são as interpretações acerca do caráter do 25 de Abril e de seus desdobramentos e consequências para o Portugal Contemporâneo. Os problemas interpretativos têm início no próprio conceito de revolução. Lembra Maria Manuela Cruzeiro, em artigo também sobre a historiografia da Revolução dos Cravos, que o termo revolução, entendido como ruptura ou marco zero, data apenas do final do século XVIII, inaugurado pela Revolução Francesa. Até então, revolução era entendida como um percurso circular, de permanente retorno, de "regresso ao ponto de partida". E os movimentos políticos e/ou sociais marcados pela ação violenta recebiam o nome de revolta, rebelião, agitação ou guerra civil. Entre os séculos XIX e XXI movimentos de matrizes e origens diversas foram entendidos como revolução. Trata-se, pois, de uma polissemia que deveria merecer atenção por parte dos estudiosos (Cruzeiro, 2011: 97-9). Outro problema, ainda de caráter metodológico, levantado por Rui Martins, encontra-se na concepção de transição, que deve ser entendida, a seu ver (e remetendo a Reinhart Koselleck), como um momento histórico marcado pela simultaneidade de histórias, ritmos e valores diversos (Martins, 2011: 19). Martins afirma ainda que esta simultaneidade não se extingue completamente a partir do momento em que a transição é concluída. Daí as dificuldades e os problemas teóricos para 0 estabelecimento de um tempo novo (Martins, 2011: 21-2).

Ainda assim, alguns historiadores insistem na demarcação. É este o caso, por exemplo, da já citada Maria Manuela Cruzeiro. Sua análise começa por criticar os modelos analíticos de Hanna Arendt e de François Furet em torno da ideia de revolução. Tanto a filósofa alemã quanto o historiador francês seriam responsáveis por um tipo de revisionismo histórico que vê na Revolução Francesa um modelo inaugural dos males que conduziram tanto ao terror de 1793-94 quanto ao Gulag soviético (Cruzeiro, 2011: 111-2). Esta literatura e os valores nela contidos teriam chegado a Portugal. Cruzeiro cita o livro de autoria de 
Rui Ramos, Bernardo Vasconcelos e Sousa e Nuno Gonçalo Monteiro, História de Portugal (2010). Critica a concepção presente no referido livro de que a Revolução portuguesa de 1974 nada mais fora que um desimportante sobressalto, "um desvio de rota a tempo corrigido". A democracia viria pois naturalmente, sem o risco de implantação de outra ditadura. Para Cruzeiro, no lugar de Michelet, Rui Ramos (o responsável pela análise do Portugal Contemporâneo no livro) seria o Tocqueville português na medida em que o discurso da ruptura não passaria de uma ilusão de mudança (Cruzeiro, 2011: 126-7). Se há continuidades entre o Antigo Regime e Bonaparte, entre o czarismo e o regime soviético, por que não haveria igualmente traços continuidade entre o Estado Novo e o consulado de Vasco Gonçalves, por exemplo? Cruzeiro faz questão de afirmar a revolução portuguesa como um novo tempo na História de Portugal. Ironias da vida, seu artigo encontra-se no mesmo livro organizado por Martins, com todas as suas questões a respeito da simultaneidade e da transição. Ao mesmo tempo em que afirma a ruptura, Cruzeiro critica aqueles que se afastam crescentemente dos "ideais de Abril" (Cruzeiro, 2011: 123). Curiosa análise essa que vê homogeneidade nos projetos que levaram à Revolução dos Cravos. É como se Mário Soares, Álvaro Cunhal, Otelo Saraiva de Carvalho ou Ernesto de Melo Antunes compartilhassem todos a mesma agenda política. Ou haveria entre eles sinceros e insinceros? Estará esta historiadora a defender a existência de um verdadeiro 25 de Abril?

Bem menos esquemático que Cruzeiro, mas ainda assim defensor da tese de ruptura, mesmo que parcialmente bloqueada, é o trabalho de Fernando Rosas. Afirma este historiador que a democracia institucionalizada em 1976, com a aprovação da nova Constituição portuguesa, "é por ela - a Revolução dos Cravos - genética e decisivamente marcada". Por este motivo, e assim como Cruzeiro, critica os diversos revisionismos que tentam tirar-lhe esta marca (Rosas, 2004a: 138). A universalização dos direitos, a integração à Europa e as diversas formas de poder local posteriormente consagradas institucionalmente foram conquistas que se mantiveram apesar da "legalidade jurídica" que se impôs sobre a "legalidade revolucionária". Sobretudo porque a democracia portuguesa, longe de ter sido outorgada, foi conquistada na rua, na revolução que se seguiu ao golpe de 25 de Abril de 1974 (Rosas, 2004a: 154-5). Esta conquista democrática pode ser exemplificada no comportamento popular a partir da queda do regime: invasão da sede da PIDE, dos órgãos de censura, concentração em frente aos fortes de Peniche e Caxias exigindo a libertação de todos os presos políticos. Por fim, as conquistas das liberdades fundamentais que se mantiveram após 1976. Em diversos aspectos e momentos, a radicalização popular ultrapassou a vontade e os programas dos partidos políticos, que em muitos casos tentaram conter a ação "autônoma" da população (Rosas, 2004a: 138-43). Isto para não falar das lutas em torno da reforma agrária e da ocupação de apartamentos e 
casas nos centros urbanos, nomeadamente Lisboa. Temas esses afirmadores de uma ruptura e presentes em importantes estudos de outros autores (Almeida, 2006; Hammond, 1988).

As análises acima apresentadas, umas mais, outras menos esquemáticas, apontam, pois, para o 25 de Abril como um momento de quebra de continuidade em relação ao passado. Um novo tempo que surgia. Muito provavelmente não deixam de ter razão. Ainda assim, é necessário atentar para a construção histórica deste marco zero. 0 fato de a tradição ser inventada, como afirmam Hobsbawm e Ranger (1984), não significa que ela seja ilegítima. Esta é a perspectiva apontada, por exemplo, por António Costa Pinto. Para este autor, a revolução portuguesa foi um processo marcado por ambiguidades e contradições. Por projetos que tanto se aproximavam quanto divergiam. Assim, o olhar e o comportamento sobre a data inaugural, o 25 de Abril, foram alterados de acordo com a conjuntura. Ainda que permaneça um discurso generalizante a respeito do 25 de Abril como uma data símbolo, merecedora do feriado que the foi outorgado em substituição ao 28 de maio, a data inaugural da ditadura militar que deu origem ao Estado Novo no ano de 1926. No entanto, a hegemonia de setores mais ou menos radicais, mais ou menos moderados ou mais ou menos conservadores permitiu ações que se alteraram com o tempo. Saneamentos contra funcionários do "regime fascista" ou anistias políticas, criação de espaços de memória, como é o caso do Museu da Resistência, ou a alteração do nome da ponte 25 de Abril (antes Oliveira Salazar) decorrem de disputas pela memória. Sempre inconclusas ou em busca de uma legitimidade que necessariamente se altera com o passar do tempo e dos anos (Pinto, 2004: 87-153; Pinto, 2014). Como pano de fundo para o entendimento do 25 de Abril, o fato de que a Revolução ocorre a partir de uma "crise do Estado", ao contrário, por exemplo, das transições espanhola ou brasileira. Não se trata, pois, de uma transição melhor ou pior, mas de outra forma de transição. Esta é, entretanto, uma perspectiva de análise ainda pouco explorada, mas que aponta no sentido da quebra da forçada dicotomia entre verdadeira e falsa revolução.

\section{Conclusão}

E sta análise, longe de ser conclusiva, pretendeu apresentar um breve panorama dos modelos que informam parte dos estudos em torno da Revolução dos Cravos. De um lado, não deixa de ser curiosa a persistência de um olhar marcadamente militante. Ou será, ao contrário, que este fenômeno é mais ou menos comum? Afinal, não foi assim também quando das comemorações do bicentenário da Revolução Francesa? Elas não cindiram corações e mentes? (Vovelle, 1989). De qualquer forma, o que é importante nessas interpretações marcadas por certo engajamento é a ideia segundo a qual revolução e transição são inconciliáveis. Claro 
é que não me refiro aqui à totalidade dos estudos que optam pela ênfase em certa ideia de ruptura. Ainda assim, ouso afirmar que se trata de larga maioria. Mais um aspecto importante é a centralidade no marcelismo para o entendimento da Revolução. A transição falhada ou a tentativa de alguma mudança "para que tudo permaneça como está" é tema que permanece como polêmica viva entre os historiadores portugueses.

Por fim, vale enfatizar que os estudos em torno do 25 de Abril de 1974 não se esgotaram. Como tratei aqui dos processos "endógenos", cito dois importantes exemplos: de um lado, o papel da mulher ou da cultura, de outro, a ambivalência do marcelismo ou os marcos de um país eventualmente dual merecem maiores investigações por aqueles preocupados com a transição portuguesa para a democracia.

\section{REFERÊNCIAS BIBLIOGRÁFICAS}

ALMEIDA, M. A. P. A revolução no Alentejo: memória e trauma da reforma agrária em Aviz. Lisboa: Imprensa de Ciências Sociais, 2006.

BERMAN, M. Tudo que é sólido desmancha no ar. A aventura da Modernidade. São Paulo: Companhia das Letras, 1986.

CARVALHO, O. S. Alvorada em Abril. 3a ed. Lisboa: Ulmeiro, 1984.

CARVALHO, R. A. A definição do marcelismo à luz da revisão constitucional. In: ROSAS, F. \& OLIVEIRA, P. A. (coord.). A transição falhada: o marcelismo e o fim do Estado Novo (1968-1974). Lisboa: Editorial Notícias, 2004, p. 27-89.

CORKIL, D. 0 desenvolvimento económico português no fim do Estado Novo. In: ROSAS, F. \& OLIVEIRA, P. A. (coord.). A transição falhada: o marcelismo e o fim do Estado Novo (1968-1974). Lisboa: Editorial Notícias, 2004, p. 213-232.

CRUZEIRO, M. M. "Revolução" e revisionismo historiográfico. 025 de Abril visto da História. In: MARTINS, R. C. (coord.). Portugal, 1974: transição política em perspectiva histórica. Coimbra: Editora Universidade de Coimbra, 2011, p. 97-134.

FERNANDES, Tiago. Nem ditadura, nem revolução. A Ala Liberal e o Marcelismo (1968-1974), Lisboa: D. Quixote/Assembleia da República, 2006.

HAMMOND, J. L. Building Popular Power: Workers' and Neighborhood Movements in the Portuguese Revolution. New York: Montly Review Press, 1988.

HOBSBAWM, E. \& RANGER, T. (orgs.). A invenção das tradições São Paulo: Paz e Terra, 1984.

MARCHI, R. Império, nação, revolução - as direitas radicais portuguesas no fim do Estado Novo (1959-1974). Lisboa: Texto Editores, 2009.

. Nacionalismo revolucionário na crise do Império. In: MARCHI, R. (org.). As raízes profundas não gelam: ideias e percursos das direitas portuguesas. Alfragide: Texto Editores, 2014, p. 327-356. 
MARTINHO, F. C. P. Entre o fomento e o condicionamento: a economia portuguesa em tempos de crise. In: MARTINHO, F. C. P. \& LIMONCIC, F. (org.). A Grande Depressão: política e economia na década de 1930 - Europa, Américas, África e Ásia. Rio de Janeiro: Civilização Brasileira, 2009, p. 305-330.

MARTINS, R. C. Problemática da mudança política. In: MARTINS, Rui Cunha (coord.). Portugal, 1974: transição política em perspectiva histórica. Coimbra: Editora Universidade de Coimbra, 2011, p. 19-29.

PINTO, A. C. Ajustando as contas com o passado na transição para a democracia em Portugal. In: BRITO, A. B; GONZÁLEZ-ENRÍQUEZ, C. \& FERNÁNDEZ, P. A. (coord.). Política da memória: verdade e justiça na transição para a democracia. Lisboa: Imprensa de Ciências Sociais, 2004, p. 87-153.

_—. 25 de Abril - 40 anos. Lisboa: Clube do Colecionador dos Correios, 2014.

—. A busca da democracia, 1960-2000. Lisboa: Objectiva/Fundação Mapfre, 2015.

\& TEIXEIRA, N. S. A Europa do Sul e a construção da União Europeia (1945-2000). Lisboa: Imprensa de Ciências Sociais, 2005.

PROENÇA M. C. A reforma educativa de Veiga Simão. In: ROSAS, F. \& OLIVEIRA, P. A. (coord.). A transição falhada: o marcelismo e o fim do Estado Novo (1968-1974). Lisboa: Editorial Notícias, 2004, p. 233-261.

RAMOS, R.; SOUSA, B. V. \& MONTEIRO, N. História de Portugal. 5a ed. Lisboa: Esfera dos Livros, 2010.

REIS, J. M. A transição impossível. A ruptura de Francisco Sá Carneiro com Marcello Caetano. Lisboa: Casa das Letras, 2010.

ROSAS, F. Pensamento e acção política: Portugal, século XX (1890-1976). Lisboa: Editorial Notícias, 2004a.

Marcelismo: ser ou não ser. In: ROSAS, F. \& OLIVEIRA, P. A. (coord.). A transição falhada: o marcelismo e o fim do Estado Novo (1968-1974). Lisboa: Editorial Notícias, 2004b, p. 9-26.

SANTOS, P. B. A segunda separação: a política religiosa do Estado Novo (1933-1974). Lisboa: Almedina, 2016.

SCHMITTER, P. C. Portugal: do autoritarismo à democracia. Lisboa: Imprensa de Ciências Sociais, 1999.

SILVA, F. C. Teixeira da. Europa ou o concerto das nações. Ideias conservadoras e política internacional na obra de Leopold von Ranke (1795-1886). Tese apresentada ao Concurso Público para Professor Titular de História Moderna e Contemporânea da Universidade Federal do Rio de Janeiro - UFRJ. Rio de Janeiro, 1993.

TEIXEIRA, N. S. The Europeanization of Portuguese Democracy. New York: Columbia University Press, 2012.

TORGAL, L. R. Marcelismo, "Estado social" e Marcello Caetano. In: Estado Novo, Estados Novos. Volume I. Coimbra: Editora Universidade de Coimbra, 2009, p. 615-73.

VOVELLE, Michel. A Revolução Francesa e seu eco. Estudos Avançados. Vol. 3, no 6, p. 25-45, 1989. 
